\title{
Patient-Centered Outcomes with Pituitary and Parasellar Disease
}

\author{
Susan M. Webba, Alicia Santos ${ }^{a, b}$ Anna Aulinas ${ }^{a, b}$ Eugenia Resmini ${ }^{a, b}$ \\ Luciana Martel $^{a}$ María-Antonia Martínez-Momblán ${ }^{b, c}$ Elena Valassia, b \\ aDepartment of Medicine/Endocrinology, IIB-Sant Pau, Hospital Sant Pau, Research Center for Pituitary Diseases, \\ Barcelona, Spain; bCentro de Investigación Biomédica en Red de Enfermedades Raras (CIBERER, Unidad 747), ISCIII, \\ Universitat Autònoma de Barcelona (UAB), Barcelona, Spain; ' $D$ Department of Fundamental and Medico-Surgical \\ Nursing, School of Medicine and Health Sciences, University of Barcelona, Barcelona, Spain
}

\section{Keywords}

Quality of life - Acromegaly - Cushing syndrome ·

Hypopituitarism · Pituitary adenoma

\section{Abstract}

Over the last 2 decades, advances in the diagnosis and management of pituitary diseases have made it possible to attain an endocrine "cure" in a large proportion of patients. In other words, tumors can be excised or controlled with drugs, mass effects of the lesion on surrounding structures can be solved, and pituitary deficiencies can be substituted with all relevant hormones. While this is considered a satisfactory outcome for health care providers, patients often suffer from an aftermath of prior endocrine dysfunction exposure, with irreversible effects, both physically and psychologically, which have a great impact on their everyday life. Diagnostic delay, often of several years, adds a negative impact on health perception. This affects their social, professional, and family domains and determines their future life. Understanding that this may occur is important, and health care providers should offer information to prepare the patient for this difficult journey, especially in the case of acromegaly, Cush- ing disease, or hypopituitarism. In order to maintain a good quality of life (QoL) in the long-term, patients need to adapt to this new situation, something that may be difficult, since they often cannot continue with all the activities and rhythm they used to do. Depression is often the consequence of maladaptation to the new situation, leading to impaired QoL.

(c) 2020 S. Karger AG, Basel

\section{Introduction}

Quality of life (QoL) does not mean the same for a health care provider and for a patient. An endocrinologist considers pituitary disease to be controlled if pituitary hormone function is normal and tumor growth is stable; with current surgery and medical therapy, this is possible nowadays in most patients. However, patients would like to perform daily activities as they did prior to suffering from pituitary disease, personally and professionally, without physical or psychological limitations, pain, or social or family problems related to their disease; if this is not the case, the patient will hardly consider himself "cured" or experience a good health-relat- 
ed QoL. They want to feel healthy, independently of what the hormone or imaging results show. These subjective feelings of health perception of the patient can be measured with patient-reported outcome (PRO) questionnaires, and they are contemplated by administrators and regulating agencies when considering health-related decisions, that is, authorizing reimbursement of new drugs or devoting health resources to a particular group of patients.

Questionnaires are more and more frequently used to evaluate QoL and the long-term impact on health perception after suffering pituitary dysfunction [1]. It is now evident that years after "curing" pituitary dysfunction, patients still suffer from more cardiovascular, skeletal, and neuropsychological morbidity (i.e., worse executive function, emotional coping leading to anxiety, depression, and psychological distress, as well as memory and cognition complaints), especially after hypercortisolism of the Cushing syndrome/Cushing disease (CD; of either pituitary or adrenal origin, or after exogenous treatment with high doses of glucocorticoids and/or long-term exposure), acromegaly, or hypopituitarism [2-10]. Patients complain of impaired QoL related to dimensions vital for daily life, which are often ignored by clinicians [3]. Common complaints are physical (poor stamina, body image, and libido) and emotional (slower on the uptake, anxiety, or depression), and less frequently social issues, although visual or other problems, which prevent driving, do have a great negative impact $[1,2]$.

Working disability (no paid job, need of sick leave, or not being productive while at work due to difficulties in concentrating and losing the train of thought) is common in patients with pituitary tumors; furthermore, patients with a paid job experience a better QoL than those who are unemployed [11]. Patients with a diagnosis of hypopituitarism, acromegaly, or CD experience more working problems than those with nonfunctioning pituitary adenomas (NFPA) or Rathke's pouch cysts. Current use of medical therapy or having undergone radiotherapy impact more negatively than being controlled after surgery. Higher education and income levels, as well as being married or with a stable relationship, are also associated with a greater probability of being employed [11]. These persistent limitations after pituitary disease explain the greater probability of early retirement, shorter working hours, or the need of adapting jobs to persistent limitations in patients with pituitary disease. Thus, any initiatives that favor a better adaptation to the current situation will be beneficial not only for the individual patient but also for society at large.

Patient-Centered Outcomes with Pituitary and Parasellar Disease

\section{Comparison of the Impact of Different Pituitary Diseases on Patients' Health Perception}

As any other chronic health process, pituitary diseases may affect everyday life. Features like female gender, older age, hypopituitarism, active disease, depressive symptoms, negative illness perceptions, prior radiotherapy, tumor recurrence, and frequent checkups negatively affect perceived health and QoL, and are common to all pituitary diseases. Other features that affect QoL are specific to acromegaly, $\mathrm{CD}$, or adult growth hormone deficiency, situations where QoL is more impaired than in NFPA or prolactinomas $[1,12-20]$.

The individual patient tends to adapt to perceived limitations with more or less success. With good adaptation, perceived QoL may be quite acceptable despite persistent morbidity, while maladaptation usually leads to frustration, anxiety, or depression, and worse QoL. Educating patients on the nature and consequences of pituitary diseases by multidisciplinary teams (including endocrinologists, neurosurgeons, neuroradiologists, psychologists, and endocrine nurses) is helpful to understand the nature and adapt to limitations [21]. The patients' family and social environment can also play a positive role on patient outcome and help to accept the new situation by showing understanding, comprehension, support, and a positive approach to day-to-day life [22].

In a pilot study carried out when patients attended their outpatient appointment during 2019, they were asked to describe how their pituitary disease had affected their everyday life using a structured interview (see online supplementary data, for all online supplementary material see www.karger.com/doi/10.1159/000506809) [Santos et al., unpubl. results]. Fifty-four patients were interviewed, 14 patients diagnosed with CD, 14 with acromegaly, 14 with prolactinoma, and 12 with NFPA (Table 1 ).

CD patients had the greatest impact of the disease on their life (7.5 out of a maximum of 10), followed by prolactinoma (6.8), acromegaly (6.5), and NFPA (5.8; Fig. 1a). In the case of prolactinomas, they were mostly large macroadenomas, 8 of them in males with invasive lesions. In acromegaly, women declared to have experienced a much greater impact than men ( 8.9 vs. 4.2$)$, while clear gender differences were not observed in other diagnostic groups (Fig. 1b).

Emotional complaints in these 54 patients were globally more prevalent at diagnosis, but they were still quite prevalent during the interview at follow-up (Table 2). At diagnosis, only 18 (33\%) recalled to have felt fine, while at the follow-up 33 (61\%) referred to feel happy and fine.

Neuroendocrinology 2020;110:882-888 
Table 1. Physical impact referred by patients with different pituitary diseases at diagnosis and during the recent interview

\begin{tabular}{ll}
\hline At diagnosis & During the interview \\
\hline Cushing disease ( $n=14,3$ males; aged 27-75 years) & \\
1 on cortisol-lowering drugs; substitution therapy: 3 GH; 8 & L-thyroxine; 3 hydrocortisone; 1 testosterone \\
Swollen (7) & Feeling fine (5) \\
Increased weight (5) & Feeling tired (6) \\
Excessive fatigability (3) & Would prefer to be thinner/less swollen (3) \\
Body shape (3) & Pain (2) \\
Hirsutism (3) & More visceral fat \\
Bruising (3) & Heart/walking problems \\
Pain (2) & Sleeping difficulties \\
Sleeping difficulties (2) & Curly hair (after radiotherapy) (2) \\
Menstrual irregularities (2) & Feeling very cold \\
& Desire for plastic surgery to recover body image
\end{tabular}

Acromegaly ( $n=14,7$ males; aged 35-66 years)

3 on GH-lowering drugs; substitution therapy: $4 \mathrm{GH}$; 5 L-thyroxine; 4 hydrocortisone; 3 testosterone

Ok, minor changes perceived (3)

Changes in facial features (3)

Increase in the size of hands and feet (2)

Feeling tired (2)

Too tall (2)

Pain (2)

Swollen (2)

Feeling fine (3)

Pain (7)

Cannot recognize myself in the mirror

Feeling tired

Abdominal discomfort with oral medication

Desire for plastic surgery to recover body image

Loss of vision

Prolactinomas ( $n=14,8$ males; aged $27-61$ years)

11 on prolactin-lowering drugs; substitution therapy: $1 \mathrm{GH}$; 4 L-thyroxine; 3 hydrocortisone; 2 testosterone

Headache (6)

Menstrual irregularities (5)

Loss of vision (5)

Low sexual desire (4)

Feeling tired (2)

Galactorrhea (2)

Increase in breast size $(3 ; 2 \lesssim)$

Swollen and increased weight (2)

Pain

Sterility

Nonfunctioning adenomas ( $n=12,8$ males; aged 33-78 years)

Substitution therapy: $3 \mathrm{GH}$; 4 L-thyroxine; 4 hydrocortisone; 5 testosterone

Feeling fine

Headache (8)

Loss of vision (5)

Dizziness (2)

Pain (2)

Vomiting (2)

Feeling fine (7)

Loss of vision (2)

Feeling tired (2)

Desire for plastic surgery to recover body image

Substitution therapy is imperfect

Feeling tired

Nausea

Impotence, no ejaculation

The numbers in parentheses correspond to the individuals who indicated having experienced the symptom or problem specified; otherwise only 1 individual reported the problem. GH, growth hormone. 
Fig. 1. a Patient's subjective impression on the impact of different pituitary diseases on everyday life (maximum impact 10, minimum 0). b Women with acromegaly refer a much greater impact of their disease than men, while this sexual dimorphism was not observed in other diseases. CD, Cushing disease; ACR, acromegaly; PRL, prolactinoma; NF, nonfunctioning adenomas.
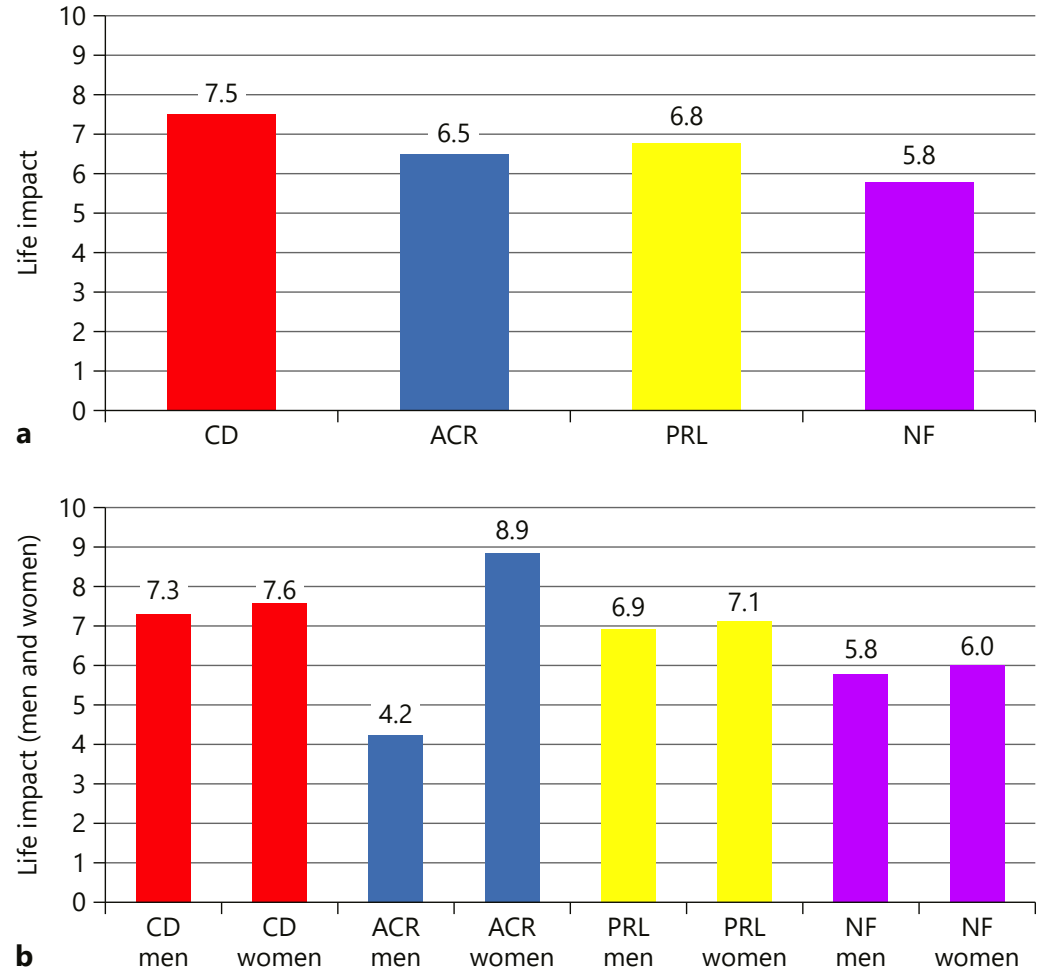

Table 2. Emotional complaints at diagnosis and during the interview (all 54 patients together, Cushing disease, acromegaly, prolactinoma, and nonfunctioning adenoma)

\begin{tabular}{ll}
\hline At diagnosis & During the interview \\
\hline Feeling fine (18) & Feeling fine (30) \\
$\begin{array}{l}\text { Depression (7)/sadness (5) } \\
\text { Fear (5) }\end{array}$ & Dappy (3) \\
Mood swings (4) & Nervousness/anxiety (3) \\
Irritability (3)/anger (2) & Dislike of my body (3) \\
Apathy (2) & Sadness/depression (5) \\
Anguish (2) & Mood swings (3) \\
Nervousness (2)/anxiety & Worried about medical controls (2) \\
Difficulty concentrating & Fear (2) \\
Feeling worried & Feeling lonely \\
Low self-esteem & \\
\hline
\end{tabular}

Thus, despite improvement, more than half still experienced emotional discomfort, including anxiety, depression, sadness, nervousness, mood swings, worry, fear, lack of initiative, loneliness, or dislike of body image after treatment.

Social issues at diagnosis and during the interview are globally reported in Table 3. At diagnosis, $70 \%$ did not recall any social issues, while $14(26 \%)$ referred not wanting or experiencing difficulties in going out for different reasons both physically and psychologically. At followup, the situation had improved, since 44 patients (81\%) referred no problem.

\section{Promoting Patient Empowerment by the Health Care Providers}

Perception of outcome after treatment of pituitary diseases is often overlooked or ignored by health care providers unless specifically mentioned. Patients struggle with QoL issues and miss understanding: they feel isolated, lonely, and scared, not knowing how to best manage their perceived declining health in the future. Listening to the experiences of "cured" patients (individually or through patient associations) are very illustrative and deserve more attention than given up to now. For example, patients often state that they were hardly listened to, and since they were endocrinologically "cured," their complaints were not considered. This generates anxiety, feeling bewildered, or hypochondriac. If patients are made aware that some of their perceived problems may be re- 
Fig. 2. Subjective impression of body image while actively cushingoid (a) and 2 years after successful surgery (b), as drawn by a 20 -year-old graphic designer. The author provided written consent to publish her drawings.

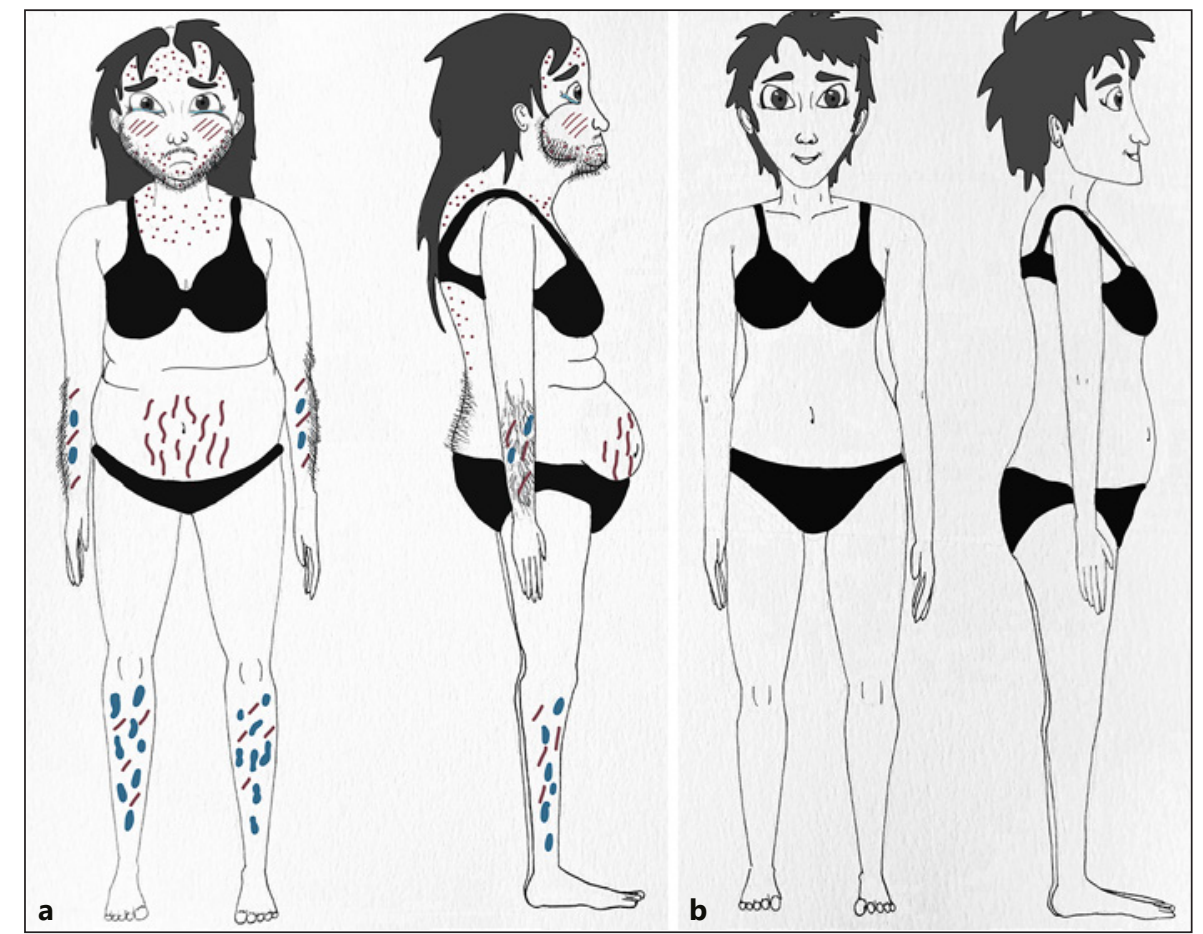

Table 3. Social issues at diagnosis and during the interview (all 54 patients together, Cushing disease, acromegaly, prolactinoma, and nonfunctioning adenoma)

\begin{tabular}{ll}
\hline At diagnosis & During the interview \\
\hline No impact (38) & No problems (44) \\
Problems with family/partner (2) & No sexual desire, leading to problems with partner \\
Going out less (11) & Going out less (3) \\
Only as an obligation (3) & It is too much of an effort \\
Only when others proposed it (2) & I cannot follow the pace anymore/ \\
Due to my physical appearance (4) & I have adapted to activities for older people \\
$\begin{array}{l}\text { Due to difficulties walking } \\
\text { Because feeling unwell }\end{array}$ & It is just too tiring \\
Did not want to go out (3) & Do not want to go out, it involves too much effort (2) \\
& Often go out with family and friends (4) \\
\hline
\end{tabular}

lated to the prior diagnosis, it allows them first to recognize a problem they are experiencing, with a reason and explanation, which they can, therefore, try to tackle. This gives them peace of mind, energy, and hopes that is often perceived as therapeutic, with a sense of relief, since they find a confirmation that their feelings are real and not imaginary.

In the words of some cured CD patients, the discussion on how challenging the recovery may be after surgery helps normalize an often very difficult journey. Just knowing that someone understands the physical and psychological devastating aftermath of chronic high cortisol levels and what they are going through is very therapeutic, with a feeling of being validated and understood. Furthermore, the devastating changes induced by hypercortisolism on body image are very distressing, as illustrated by a young graphic designer who drew herself as she recalled she was prior to treatment and 2 years later when her adrenal axis was normal (Fig. 2).

Education and/or information by devoted and empathic multidisciplinary teams with an understanding of these persistent issues facilitate an adaptation to these limitations, making the patients aware that this may occur. Additionally, understanding and a positive approach 
to day-to-day life, comprehension, and support from family or friends contribute to accept this new situation, affecting positively patients' health perception and longterm prognosis.

Patients appreciate that health care providers be patient and encouraging, since they often cannot grasp all the implications a prior diagnosis of pituitary disease may have. It takes time for them to accept the whole situation and adapt to it, especially when they do not feel "normal and healthy." Most appreciate receiving complete written information on their diseases and the consequences it may have, although each individual is unique. Being kind, empathic, and listening to the patients to identify specific issues which can be dealt with is much appreciated and helps them feel better. For some, contacting other patients through patient associations, forums, Facebook, or social network groups is very helpful.

\section{Conclusion}

Patient-centered outcome measures, including evaluation of QoL, complement biochemical and radiological workup of pituitary patients. Health perception is worse in active disease, especially with hypercortisolism due to $\mathrm{CD}$, acromegaly, and hypopituitarism, and is often still impaired, even in the presence of endocrine "cure." Preexisting psychopathology, like anxiety, depression, or an irritable mood, further worsen QoL, while adaptation to the new physical, psychological, or social limitations are associated with better health perception and QoL. From a practical point of view, QoL questionnaires can identify issues not discussed during the clinical interview and can alert the health care provider of problems like anxiety, depression, or personal concerns, which can be discussed and explained to the patients. This alone can be very therapeutic since the patient feels validated and relieved that the problems or concerns are real and related to their disease. Identification of persistent anxiety and depression, for example, with a simple and easily accessible questionnaire like HADS (Hospital Anxiety and Depression Scale) can classify those individuals who may benefit from psychological or psychiatric help to overcome their problem. A supportive social or family environment can also be helpful, which can be favored by informing and educating the patients and their environment on the nature of their pituitary disease and what to expect after so-called successful treatment.

\section{Acknowledgment}

The authors are indebted to Ms. Ariadna Corretja for her drawings on how one feels before and after successful CD surgery.

\section{Disclosure Statement}

The senior author (S.M.W.) is the co-author and co-owner of the copyright of disease-specific QoL questionnaires (AcroQoL and CushingQoL), as illustrated in the reference list. The other authors have no conflicts of interest to declare.

\section{Funding Sources}

This review, which has received no funding, was prepared after being awarded the Rolf Gaillard prize of the European Neuroendocrine Association and presenting a lecture at the 6th ENEA Workshop on Parasellar Lesions in Athens in December 2019.

\section{Author Contributions}

S.M.W. has written this review. All authors have contributed data, performed critical reading, and helped with the revision of the manuscript, as well as approved the final version.

\section{References}

Patient-Centered Outcomes with Pituitary and Parasellar Disease
1 Webb SM, Crespo I, Santos A, Resmini E, Aulinas A, Valassi E. MANAGEMENT OF ENDOCRINE DISEASE: quality of life tools for the management of pituitary disease. Eur J Endocrinol. 2017 Jul;177(1):R13-26.

2 Romijn JA. The chronic syndromes after previous treatment of pituitary tumours. Nat Rey Endocrinol. 2016 Sep;12(9):547-56.

3 Andela CD, Scharloo M, Pereira AM, Kaptein AA, Biermasz NR. Quality of life (QoL) impairments in patients with a pituitary adenoma: a systematic review of QoL studies. Pituitary. 2015 Oct;18(5):752-76.
4 Koltowska-Häggström M, Mattsson AF, Monson JP, Kind P, Badia X, Casanueva FF, et al. Does long-term GH replacement therapy in hypopituitary adults with GH deficiency normalise quality of life? Eur J Endocrinol. 2006 Jul;155(1):109-19.

5 Mo D, Blum WF, Rosilio M, Webb SM, Qi R, Strasburger CJ. Ten-year change in quality of life in adults on growth hormone replacement for growth hormone deficiency: an analysis of the hypopituitary control and complications study. J Clin Endocrinol Metab. 2014 Dec; 99(12):4581-8. 
6 Koltowska-Häggström M, Mattsson AF, Shalet SM. Assessment of quality of life in adult patients with GH deficiency: KIMS contribution to clinical practice and pharmacoeconomic evaluations. Eur J Endocrinol. 2009 Nov;161 Suppl 1:S51-64.

7 Webb SM, Badia X. Quality of life in acromegaly. Neuroendocrinology. 2016;103(1):10611.

8 Tiemensma J, Kaptein AA, Pereira AM, Smit JW, Romijn JA, Biermasz NR. Affected illness perceptions and the association with impaired quality of life in patients with longterm remission of acromegaly. J Clin Endocrinol Metab. 2011 Nov;96(11):3550-8.

9 Sievers C, Ising M, Pfister H, Dimopoulou C, Schneider HJ, Roemmler J, et al. Personality in patients with pituitary adenomas is characterized by increased anxiety-related traits: comparison of 70 acromegalic patients with patients with non-functioning pituitary adenomas and age- and gender-matched controls. Eur J Endocrinol. 2009 Mar;160(3):36773.

10 Santos A, Resmini E, Gómez-Ansón B, Crespo I, Granell E, Valassi E, et al. Cardiovascular risk and white matter lesions after endocrine control of Cushing's syndrome. Eur J Endocrinol. 2015 Dec;173(6):765-75.

11 Lobatto DJ, Steffens AN, Zamanipoor Najafabadi AH, Andela CD, Pereira AM, van den Hout WB, et al. Work disability and its determinants in patients with pituitary tumor-related disease. Pituitary. 2018 Dec;21(6):593604.
12 Wexler T, Gunnell L, Omer Z, Kuhlthau K, Beauregard C, Graham G, et al. Growth hormone deficiency is associated with decreased quality of life in patients with prior acromegaly. J Clin Endocrinol Metab. 2009 Jul;94(7): 2471-7.

13 Badia X, Forsythe A, Nelson LM, Coles TM, McLeod LD, Webb SM. Improvements in health-related quality of life in acromegaly with pasireotide LAR and octreotide LAR: results from a large, randomized, double-blind phase III trial. In Poster Presented at the International Society for Pharmacoeconomics and Outcomes Research (ISPOR), Berlin, Germany, 3-7 November 2012. Value Health. 2012;15:A505.

14 Neggers SJ, van Aken MO, de Herder WW, Feelders RA, Janssen JA, Badia X, et al. Quality of life in acromegalic patients during longterm somatostatin analog treatment with and without pegvisomant. J Clin Endocrinol Metab. 2008 Oct;93(10):3853-9.

15 Sibeoni J, Manolios E, Verneuil L, Chanson P, Revah-Levy A. Patients' perspectives on acromegaly diagnostic delay: a qualitative study. Eur J Endocrinol. 2019 Jun;180(6):339-52.

16 van Aken MO, Pereira AM, Biermasz NR, van Thiel SW, Hoftijzer HC, Smit JW, et al. Quality of life in patients after long-term biochemical cure of Cushing's disease. J Clin Endocrinol Metab. 2005 Jun;90(6):3279-86.
17 Valassi E, Feelders R, Maiter D, Chanson P, Yaneva M, Reincke M, et al.; ERCUSYN Study Group. Worse Health-Related Quality of Life at long-term follow-up in patients with Cushing's disease than patients with cortisol producing adenoma. Data from the ERCUSYN. Clin Endocrinol (Oxf). 2018 Jun;88(6):787-98.

18 van der Klaauw AA, Kars M, Biermasz NR Roelfsema F, Dekkers OM, Corssmit EP, et al. Disease-specific impairments in quality of life during long-term follow-up of patients with different pituitary adenomas. Clin Endocrinol (Oxf). 2008 Nov;69(5):775-84.

19 Andela CD, Lobatto DJ, Pereira AM, van Furth WR, Biermasz NR. How non-functioning pituitary adenomas can affect health-related quality of life: a conceptual model and literature review. Pituitary. 2018 Apr;21(2): 208-16.

20 Liu S, Adelman DT, Xu Y, Sisco J, Begelman SM, Webb SM, et al. Patient-centered assessment on disease burden, quality of life, and treatment satisfaction associated with acromegaly. J Investig Med. 2018 Mar;66(3):65360.

21 Martínez-Momblán MA, Gómez C, Santos A, Porta N, Esteve J, Úbeda I, et al. A specific nursing educational program in patients with Cushing's syndrome. Endocrine. 2016 Jul; 53(1):199-209.

22 Santos A, Webb SM. Coping with Cushing's disease: the patients' perspectives. In: Laws ER, editor. Cushing's disease. An often misdiagnosed and not so rare disorder. Amsterdam: Elsevier; 2017. p. 169-85. 